\title{
UM OLHAR ESTILÍSTICO SOBRE A LETRA DA CANÇÃO A TRISTE PARTIDA (TEA
}

Maria Lidiane de Sousa Pereira* Rakel Beserra de Macêdo Viana** Yone Alencar Coelho*** Edna Duarte Ribeiro****

RESUMO: À luz da Estilística do som ou Fonoestilística (BALLY, 1941, 1951; GRAMMONT, 1975; GILI, 1971; MORIER, 1975; MARTINS, 2000), analisamos, neste trabalho, a letra da canção $A$ triste partida, cantada por Luiz Gonzaga - conhecido também como o Rei do Baião. Nosso objetivo é descrever e refletir sobre os efeitos estilísticos/expressivos dos recursos fonético-fonológicos, como fonemas e figuras do som, presentes na letra da canção. Para tanto, observamos as estrofes que compõem a letra de $A$ triste partida e descrevemos alguns dos principais recursos estilísticos/expressivos que a compõem. As análises indicam a presença de recursos da linguagem estilística/expressiva tais como homeoteleuto, rimas, aliteração, assonância, alterações fonéticofonológicas em alguns vocábulos, dentre outros.

PALAVRAS-CHAVE: Estilística do som; A triste partida; Análise.

\section{INTRODUÇÃO}

Este trabalho apresenta uma análise estilística da letra da canção $A$ Triste Partida ${ }^{1}$, interpretada pelo cantor e compositor brasileiro Luiz Gonzaga - conhecido também como o Rei do baião. O objetivo é analisar alguns dos fenômenos estilísticos/expressivos presentes na letra da canção, com ênfase maior no nível

\footnotetext{
*Doutoranda em Linguística Aplicada na Universidade Estadual do Ceará. E-mail: lidiane lidiarock@hotmail.com.

**Mestranda em Linguística Aplicada pela Universidade Estadual do Ceará. E-mail: rakelbeserra@gmail.com.

***Graduada em Letras pela Universidade Regional do Cariri (URCA), Crato - CE. E-mail: yone.coelho@gmail.com.

${ }_{* * *}$ Graduada em Letras pela Universidade Regional do Cariri (URCA), Crato - CE. E-mail: ednaduarte1996@gmail.com.

1 O leitor pode ter acesso à canção, na íntegra, através do seguinte endereço: https://www.youtube.com/watch?v=Yu0bvuK8s_k.
} 
fonético-fonológico. A premissa inicial que move este estudo é a de que algumas das potencialidades estilísticas/expressivas dos elementos fonético-fonológicos da língua portuguesa aparecem na letra da canção com o intuito de intensificar os sentimentos de saudade, tristeza e angústia que acometem os personagens da canção ao precisarem deixar a terra natal por causa dos longos períodos de seca que atingiam/atingem algumas localidades da região nordeste brasileiro e que eram/são agravados pelo descaso político. De igual modo, acreditamos que alguns recursos estilísticos/expressivos aparecem como uma tentativa de representar aspectos dialetais dos personagens.

Alicerçamos este estudo nos pressupostos teórico-metodológicos da Estilística do som ou Fonoestilística (BALLY, 1941, 1951; PORZIG, 1970; GILI, 1971; GRAMMONT, 1975; LEON, 1971; MORIER, 1975; MARTINS, 2000). Como o próprio nome sugere, essa área do conhecimento figura como uma das principais vertentes da Estilística da língua ou descritiva (BALLY, 1941, 1951) e se volta para a observação dos efeitos estilísticos/expressivos que alguns elementos fonéticofonológicos podem suscitar em alguns discursos.

Além desta introdução e das considerações finais, este artigo está dividido em mais duas partes. Em Sobre a Estilística do som, colocamos em discussão algumas das questões que marcam a Estilística enquanto área de estudos do fenômeno linguístico, com ênfase em sua vertente conhecida como a Estilística do som (BALLY, 1941, 1951; GRAMMONT, 1975; GILI, 1971; MORIER, 1975; MARTINS, 2000). Já em $A$ expressividade linguística em $A$ triste partida, analisamos alguns dos principais recursos estilísticos/expressivos presentes na letra da canção que tomamos para análise.

\section{SOBRE A ESTILÍSTICA DO SOM}

O termo Estilística começou a ser usado no início do século XIX. Contudo, somente no século XX passou a designar uma área de estudos do fenômeno linguístico. Hoje, enquanto área do conhecimento, a Estilística volta-se "para os fenômenos da linguagem, tendo por objeto de estudo o estilo" (MARTINS, 2000, p.1). Ao lado de tal conceituação, é possível encontrar uma série de vertentes da Estilística. Martins (2000), por exemplo, aponta, pelo menos, cinco grandes ramificações dos estudos estilísticos, a saber: a Estilística enquanto Sociolinguística (CRYSTAL; DAVY, 1969); Estilística estrutural (RIFFATERRE, 1973; LEVIN, 1975); Estilística funcional (JAKOBSON, 1970); Estilística literária (SPITZER, 1968) e Estilística da língua ou descritiva (BALLY, 1941, 1951).

Grande parte das razões pelas quais é possível identificar hoje mais de uma vertente para os estudos da Estilística, parece-nos resultar da imensa complexidade que envolve o seu próprio objeto de estudo, isto é, o estilo. Afinal, é sabido que, até os dias de hoje, não há consenso entre os estudiosos para a compreensão do fenômeno do estilo, dada a sua inegável complexidade (cf. Martins, 2000). Tendo em vista que este trabalho está amparado nos pressupostos da Estilística da língua, ressaltamos que, aqui, o estilo é pensado como um fenômeno resultante da combinação de formas linguísticas que se coadunam de modo a evidenciar, em parte, o ego e, em parte, as forças sociais as quais está submetido o falante/escrevente (BALLY, 1941, 1951). 
Neste trabalho, ênfase é dada, conforme já indicamos, à vertente da Estilística conhecida como a Estilística da língua ou descritiva, visto que nos parece ser a que melhor atende aos nossos objetivos, pois nos permite observar como recursos da linguagem estilística/expressiva atuam no sentido de realçar, complementar, ou até mesmo criar novos significados em determinados discursos (MONTEIRO, 2011). É nesse sentido que Bally (1951, p.16) compreende a Estilística descritiva como "o estudo da expressão dos fatos da língua, organizados a partir do conteúdo emocional, isto é, a expressão de fatos da sensibilidade da linguagem e da ação dos fatos da língua sobre a sensibilidade"2.

Ao focar sua atenção no chamado sistema expressivo/afetivo das línguas naturais, Bally $(1941,1951)$ reconhece o potencial estilístico/expressivo dos elementos fonético-fonológicos tanto no nível segmental, como no suprassegmental. Assim, defende que determinados sons ou fonemas são capazes de realçar - em função de sua natureza e articulação - e, até mesmo criar, determinados sentidos vinculados pelos vocábulos. Para tanto, é preciso que haja entre o 'significante' e o 'significado' algum tipo de ligação, pois os valores estilísticos/expressivos dos elementos fonético-fonológicos "só são postos em relevo pela significação" (MARTINS, 2000, p.27). Tais assertivas proporcionaram, portanto, o surgimento dos estudos da Estilística do som ou Fonoestilística, os quais foram mais bem desenvolvidos a partir dos trabalhos de Grammont (1975) e Morier (1975).

De acordo com Morier (1975), a expressividade ou potencial estilístico do segmento sonoro decorre de um encontro feliz com o significado. Nesse sentido:

Um ou outro dos caracteres constitutivos do fonetismo da palavra
considerada deve ser a imagem de um ou outro aspecto do
significado. É o sentido que serve de filtro, recusando os valores
fonéticos sem relação com os elementos do significado e exaltando
os valores concordes. Assim, o potencial de 'escuridão' da vogal /u/
se aproveita escuro, noturno, mas é recusado em luz e diurno
(MARTINS, 2000, p.27, grifos no original).

A partir disso, vemos que, dentro da perspectiva da Estilística do som, a arbitrariedade do signo linguístico defendida por Saussure (2012[1916]), não é de toda assumida. Isso porque, acredita-se que estamos lidando com algum tipo de motivação entre 'significante' e 'significado'. Desse modo, quando há algum tipo de correspondência entre esses dois elementos, dizemos que há expressividade, quando não, assumimos que a expressividade ou valor estilístico é zero, havendo, portanto, a arbitrariedade do signo linguístico, conforme Saussure ([1916] 2012).

Seguindo essa linha de raciocínio, Porzig (1970) identifica na chamada neutralização da arbitrariedade do signo linguístico, três processos através dos quais acredita que a motivação sonora acontece, são eles: imitação sonora, transferência sonora e correspondência articulatória. A primeira (imitação sonora) ocorre

\footnotetext{
${ }^{2}$ No original: "Étude des faits d'expression du language organizé du point de vue de leur contenu affective, cestà-dire l'expression des faits de la sensibilité par le language et l'action des faits de language sur la sensibilité" (BALLY, 1951, p.16, tradução nossa).
} 
basicamente quando tentamos traduzir diferentes ruídos produzidos por seres e/ou objetos por sons das línguas, como no caso das onomatopeias.

A segunda (transferência sonora) "acontece pela sugestão de impressão sensorial não auditiva através dos sons linguísticos" (MARTINS, 2000, p.28). Por exemplo, no caso da língua portuguesa, é sabido que a repetição da vogal /a/, considerada a vogal mais leve, aberta da língua, presta-se muito bem para exprimir ideias, sugestão de claridade (MARTINS, 2000). Já a terceira (correspondência articulatória), surge quando alguns movimentos produzidos pelo aparelho fonador correspondem à ideia que os vocábulos exprimem, como em beijo e suspiro (MARTINS, 2000).

Além das propostas de Bally (1941, 1951), Graummont (1975), Morier (1975) e Porzig (1970), convém mencionar algumas das contribuições de Leon (1971). Para este último, as funções da matéria fônica - objeto da Fonoestilística - podem ser dividas em dois grandes grupos: funções identificadoras do emissor e funções desempenhadas pela linguagem. No grupo das funções identificadoras do emissor, é assumido que os aspectos fônicos podem nos revelar algo sobre o estado de espírito do emissor, bem como de suas origens socioculturais, no caso de envolver aspectos dialetais, por exemplo. Já no grupo das funções desempenhadas pela linguagem, temos as questões relacionadas às funções fáticas, impressivas e metalinguísticas. Com base no que já dissemos até aqui, não é difícil concluir que, das propostas de Leon (1971), interessam à Estilística do som, os fenômenos relacionados, principalmente, às funções identificadoras do emissor.

Antes de partir para a análise dos recursos estilísticos/expressivos presentes na letra da canção $A$ triste partida, é interessante colocar para o leitor que será perceptível, em alguns momentos, o caráter interpretativo que guiou a discussão. Afinal, muito em um estudo amparado pela Estilística do som, apresenta um forte caráter hipotético, fruto, portanto, de "uma elucubração engenhosa a respeito de algo que [nem sempre] se pode comprovar objetivamente" (MARTINS, 2000, p. 28). Naturalmente, isso não nos impediu de tomar o cuidado para não cometer excessos imaginativos. Assim, buscamos sempre apoio nas propriedades físicas dos sons, no nível segmental. Afinal, ainda que não possamos comprovar objetivamente as intenções do autor, pautamos nossa análise, essencialmente, nos elementos linguísticos, materiais da letra da canção e, é a partir desses, que construímos nossa leitura.

\section{A EXPRESSIVIDADE LINGUÍSTICA EM A TRISTE PARTIDA}

O primeiro ponto que nos chama atenção na letra de $A$ triste partida é a repetição da expressão "Meu Deus, meu Deus", que aparece remetendo à ideia de clamor e tristeza. Essa expressão, ressaltamos, está presente em todas as estrofes da canção, assim como a expressão "Ai, ai, ai, ai". Essa última também nos parece sugerir a ideia de lamento, de súplica a Deus.

Por si só, a repetição do "ai" indica uma onomatopeia, fenômeno da linguagem estilística/expressiva que, em sentido estreito, pode ser definida como "[...] a reprodução de um ruído, ou mais modestamente, a tentativa de imitação de um ruído por um grupo de sons da linguagem. É a transposição na linguagem articulada humana de gritos e ruídos inarticulados" (MARTINS, 2000, p.47). No caso da letra 
da canção, entendemos que a expressão "ai" é usada com a intenção de exprimir dor, lamento e, portanto, a angústia e o sofrimento dos personagens da canção.

Tendo em vista que as expressões "Meu Deus, meu Deus" e "Ai, ai, ai, ai" aparecem, conforme já mencionamos, em todas as estrofes, podemos dizer também que elas figuram como o refrão da canção. A esse respeito, sabemos que, quando uma canção ou um poema narra uma história, ou vários acontecimentos, os versos em repetição servem para reafirmarem, para quem lê, o sentido da estrofe (no caso das canções) ou mesmo da canção como um todo.

Como podemos observar na estrofe 1, a repetição dos versos com as expressões supracitadas, abre e fecha a estrofe, conferindo harmonia e continuidade ao sentimento de tristeza que, para nós, permeia toda a letra da canção.

\section{(Estrofe 1) ${ }^{3}$}

Meu Deus, meu Deus

Setembro passou, com oitubro e novembro

Já tamo em dezembro

Meu Deus, que é de nós?

Meu Deus, meu Deus

Assim fala o pobre

Do seco nordeste

Com medo da peste

Da fome feroz

Ai, ai, ai, ai

Ainda sobre o verso "Meu deus, meu deus", percebemos que o termo 'Deus' é grafado com inicial maiúscula, o que pode indicar sentimento religioso (MARTINS, 2000). Isto acontece tanto no verso já mencionado, como em: "Meu Deus, que é de nós", também na estrofe 1 , bem como em todas as vezes que o termo aparece na canção.

Já nos versos: "Setembro passou Outubro e novembrol Já tamo em dezembro", ainda da estrofe 1, identificamos a presença de um homeoteleuto. Segundo Martins (2000, p. 40), o homeoteleuto consiste no "aparecimento de uma terminação igual em palavras próximas, sem obedecer a um esquema regular, ocorrendo ocasionalmente numa frase ou num verso". No caso dos referidos versos, percebemos a repetição de uma terminação no interior do enunciado, no caso, o segmento 'bro', nos vocábulos setembro, outubro, novembro e dezembro. O efeito estilístico/expressivo do homeoteleuto consiste no destaque da correlação entre as palavras em que se dá, "podendo também, em certos casos, contribuir para a harmonia imitativa" (MARTINS, 2000, p.41).

Outro fenômeno estilístico/expressivo bastante explorado na letra da canção e que chama atenção é a rima. A esse respeito, Infante (2004) nos diz que a rima surge por meio do relacionamento sonoro entre vocábulos de um determinado verso

\footnotetext{
${ }^{3}$ A numeração das estrofes é usada para facilitar a retomada, bem como sua identificação ao longo do texto. Frisamos que a numeração das estrofes se deu atendendo à ordem em que aparecem na letra da canção e não na ordem de comentário no texto.
} 
com os outros vocábulos em outros versos, ou mais precisamente, "na reiteração de determinados sons no fim dos versos" (INFANTE, 2004, p. 57). Trata-se, pois, de uma espécie de coincidência sonora. Sobre a presença de rimas na letra canção $A$ triste partida, vejamos as estrofes 2 e 3 :

\section{(Estrofe 2)}

A treze do mês ele fez experiença,

Perdeu sua crença

Nas pedra de sá,

Meu Deus, meu Deus

Mas nôta esperiença com gosto se agarra,

Pensando da barra

Do alegre natá

$\mathrm{Ai}$, ai ,ai, ai

\section{(Estrofe 3)}

Rompeu-se o natá, porém barra não veio,

O só, bem vermeio,

Nasceu munto além

Meu Deus, meu Deus

Na copa da mata, buzina a cigarra,

Ninguém vê a barra,

Pois barra não tem

$\mathrm{Ai}, \mathrm{ai}, \mathrm{ai}, \mathrm{ai}$

Nas estrofes 2 e 3, identificamos vários vocábulos (em destaque) assegurando a presença de rima entre os versos. Vemos também, que o local preferido para a colocação das rimas na letra da canção é o final de cada verso. Aliás, o final do verso é um lugar privilegiado para o aproveitamento da rima em canções e poemas (MARTINS, 2000). Vale mencionar ainda que, dentre as muitas propriedades estilísticas/expressivas da rima, o uso desse fenômeno no final dos versos é explorado por poetas e compositores com o intuito de conferir às suas obras mais musicalidade e harmonia entre as estrofes (MARTINS, 2000; INFANTE, 2004). De igual modo, é sabido que a rima pode desempenhar muitas funções, onde as mais conhecidas são: função hedonística, função decorativa, função expressiva e função estrutural.

De acordo com Martins (2000), a função hedonística da rima corresponde à sua capacidade de agradar o ouvido. Com a função decorativa, a rima é entendida como uma espécie de luxo, refinamento na elaboração dos versos. A função expressiva, por sua vez, compreende a capacidade que as rimas apresentam para realçar as ideias vinculadas pelos vocábulos que rimam. Já a função estrutural é responsável por "relacionar as palavras que apresentam rima, bem como de contribuir para a unidade do texto e para a facilidade de sua memorização" (MARTINS, 2000, p. 41). Embora tenhamos apontado as quatro principais funções da rima separadamente, é evidente que em um discurso cancioneiro, poético, por 
exemplo, elas estão intimamente relacionadas, visto que se concatenam e se complementam, como no caso da letra da canção $A$ triste partida.

Ainda sobre o fenômeno da rima, é interessante pontuar que podemos encontrar vários tipos de rima, os mais explorados são as chamadas rimas consoantes e toantes (MARTINS, 2000; INFANTE, 2004). Em linhas gerais, a rima consoante é caracterizada pela coincidência de fonemas a partir da vogal tônica dos vocábulos. Em sentido oposto, dizemos que há rima toante quando apenas as vogais tônicas e postônicas coincidem. Martins (2000, p.43) atenta ainda para a existência das chamadas símil-rimas, isto é, "rimas incompletas, nem consoantes, nem apenas toantes, visto que, além das vogais, há um elemento consonantal comum". Sobre a presença dos diferentes tipos de rimas na letra de $A$ triste partida, vejamos as estrofes 4 e 5 :

\section{(Estrofe 4)}

Sem chuva na terra descamba janêro,

Depois, feverêro,

E o mêrmo verão

Meu Deus, meu deus

Entoce o nortista, pensando consigo,

Diz: isso é castigo!

Não chove mais não

$\mathrm{Ai}$, ai, ai, ai

\section{(Estrofe 5)}

Apela pra maço, que é mês preferido

Do santo querido, sinhô São José,

Meu Deu, meu Deus

Mas nada de chuva! Tá tudo sem jeito,

Lhe foge do peito,

O resto da fé.

$\mathrm{Ai}, \mathrm{ai}, \mathrm{ai}, \mathrm{ai}$

Ao analisarmos os tipos de rimas presentes nas estrofes 4 e 5 , identificamos a presença das chamadas rimas consoantes como nos vocábulos janêro/ feverêro, verão/ não, consigo/castigo e preferido/ querido. Encontramos também, a presença das chamadas símil-rimas com os vocábulos jeito/ peito. Neles, percebemos que, além da coincidência entre as vogais tônicas e pretônicas, há a presença de um som consonantal incomum, isto é, o ' $t$ '.

Feitas essas considerações sobre alguns dos pontos que envolvem o uso da rima, enquanto recurso estilístico/expressivo na letra da canção $A$ triste partida, vejamos agora as estrofes 6, 7 e 8:

\section{(Estrofe 6)}


Agora pensando ele segui ôtra tria,

Chamando a famia

Começa a dizê:

Meu deus, meu Deus

Eu vendo meu burro, meu jegue e o cavalo,

Nós vamo a São Palo

Vivê ou morrê.

Ai, ai, ai, ai

(Estrofe 7)

Nós vamo a São Palo, que a coisa tá feia;

Por terras aleia

Nós vamo vagá.

Meu Deus, me Deus

Se o nosso destino não fô tão mesquinho,

$\mathrm{Ai}$, pro mêrmo cantinho

Nós torna a vortá.

$\mathrm{Ai}, \mathrm{Ai}$, ai

\section{(Estrofe 8)}

E vende o seu burro, o jumento e o cavalo,

Inté mêrmo o galo

Vendêro também,

Meu deus, meu Deus

Pois logo aparece feliz fazendêro,

Por pôco dinhêro

Lhe compra o que tem.

Ai, ai, ai, ai

Dentre os recursos estilísticos/expressivos presentes nas estrofes 6,7 e 8 , atentamos para as muitas alterações fonético-fonológicas em vocábulos, o que, aliás, acontece em praticamente todas as estrofes da canção ${ }^{4}$. De acordo com Martins (2000), as alterações fonético-fonológicas são fenômenos muito presentes na obra de autores regionalistas e possuem valor expressivo quando "têm a função de evocar o nível cultural das personagens ou marcar a língua [...] das zonas rurais ou do sertão" (MARTINS, 2000, p. 52).

De igual modo, lembramos que Leon (1971) - conforme apontamos na seção 1 deste trabalho - defende que a matéria fônica adquire valor expressivo quando intenta remeter alguns traços identificadores da origem geográfica, da classe social, dentre outros aspectos da identidade sociocultural do emissor. Essa nos parece justamente ser a intenção do compositor ao usar termos como famia e vortá, frequentemente associados à linguagem de sujeitos desfavorecidos economicamente, caso dos personagens da canção, e oriundos de algumas regiões

\footnotetext{
${ }^{4}$ Pontuamos que para não correr o risco de tornar a análise exaustiva - dado o grande número de ocorrências comentamos apenas algumas das muitas alterações fonético-fonológicas presentes na letra da canção.
} 
do interior brasileiro. Além disso, essas formas são coibidas pela chamada norma culta (FARACO, 2008), além de serem consideradas variantes estigmatizadas socialmente (BAGNO, 2016).

Ainda sobre esse ponto, não podemos deixar de ressaltar que, no discurso cancioneiro de Luiz Gonzaga, as muitas alterações fonético-fonológicas aparecem como uma tentativa de representar determinadas variedades linguísticas. Sobre esse ponto, concordamos com Bagno (2013, p.83) quando nos diz que trabalhos como os de Gonzaga "não são representações fiéis das variedades que eles supostamente veiculam. Não são nem têm que ser, já que [nesse tipo de trabalho] está presente uma intenção lúdica, artística, estética e, nem de longe um trabalho científico rigoroso".

Dito isso, sabemos que as alterações fonético-fonológicas acontecem por meio de três processos básicos: substituição/troca, supressão/queda e acréscimo (MARTINS, 2000). Desses processos, percebemos que os mais usados na letra da canção e, mais especificamente, nas estrofes 6,7 e 8, são a substituição/troca e a supressão/queda. Das alterações fonético-fonológicas que acontecem por meio da substituição, temos o uso do vocábulo mêrmo mesmo. Nele, temos a troca do 's' pelo ' $r$ '.

Dentre as alterações que ocorrem por meio da supressão/queda, destacamos os vocábulos famia familha, aleia alheia, em que percebemos a queda do 'l' e de 'Ih'. Temos também a presença dos vocábulos pôco pouco, ôtra outra, Palo Paulo, nos quais verificamos a supressão da semivogal 'u' no ditongo 'ou'. De igual modo, temos 0 uso do vocábulo fazendêro $\sim$ fazendeiro, em que identificamos a queda da semivogal 'i', no ditongo 'ei', fenômeno amplamente conhecido como monotongação, e que ocorre com frequência na oralidade (VEADO, 1983; PEREIRA, 2004; ARAÚJO, 2007, 2013; SILVA, 2004; TOLEDO, 2011).

Convém atentar ainda, para o uso do termo cantinho ao invés de 'canto', remetendo à ideia de lugar nos versos "Ai, pro mêrmo cantinhol Nós torna a vortá", presentes na estrofe 7. Com o termo cantinho, temos o estreitamento do conduto bucal ao pronunciarmos a vogal 'i' no sufixo 'inho', o que provoca uma sensação de pequenez. Além disso, o uso do termo no diminutivo nos parece marcar um sentimento de carinho pela terra natal que, em função de problemas sociais, como a seca e a pobreza, os personagens da canção estavam sendo obrigados a deixar.

Mencionados tais pontos, observemos as estrofes 9 e 10 :

\section{(Estrofe 9)}

Em um caminhão ele joga a famia;

Chegou o triste dia,

Já vai viajá.

Meu Deu, meu Deus

A seca terrive, que tudo devora,

Lhe bota pra fora

Da terra natá.

Ai, ai, ai, ai

(Estrofe 10) 
O carro já corre no topo da serra.

Oiando pra terra,

Seu berço, seu lá,

Meu Deus, meu Deus

Aquele nortista, partido de pena,

De longe inda acena:

Adeus, meu lugá!

Ai, ai, ai, ai,

Nas estrofes 9 e 10, o que nos chama atenção é a insistência no uso das oclusivas surdas 'p', 't' e da sonora 'd'. De acordo com Martins (2000, p.34, grifos nossos):

As consoantes oclusivas pelo seu traço explosivo, momentâneo, prestam-se a reproduzir ruídos duros, secos, de batida, pancadas, passos pesados [...] saliente-se que as surdas [p], [t], [k] dão uma impressão mais forte violenta, do que as sonoras [b], [d] e [g]. Várias palavras, iniciadas por consoante oclusiva bilabial são empregadas como interjeições, exprimindo uma explosão de surpresa, espanto, raiva e indignação.

Das potencialidades expressivas atribuídas às oclusivas, entendemos que seus traços explosivo e momentâneo são bem aproveitados nas estrofes 9 e 10 , principalmente no verso "Chegou o triste dia [...]". Nele, parece-nos que, embora a viagem para outra região tenha sido previamente planejada pelos personagens da canção, eles não estavam preparados psicologicamente e não desejavam deixar seu lar, gerando, assim, uma espécie de explosão do sentimento de tristeza com o dia da partida.

Já nos versos "A seca terrive, que tudo devora/ Lhe bota pra fora/ Da terra natá" percebemos uma certa acentuação dos sentimentos de raiva e indignação provocados pelo problema da seca, que obriga os personagens a deixarem sua terra natal. Tais sentimentos nos parecem ser realçados justamente pela insistência no uso das oclusivas surdas ' $p$ ', 't' e pelas sonoras ' $d$ ' e ' $b$ ', presentes na grande maioria dos vocábulos que compõem os versos em questão.

Interessante mencionar ainda que, o insistente uso das oclusivas serve não apenas para realçar a impressão de determinados sentimentos, conforme procuramos indicar nos parágrafos anteriores, mas também acaba gerando a figura de som conhecida como aliteração.

Em termos simples, pode-se entender por aliteração "a repetição de um som [consonantal] ou de um grupo de sons [consonantais] no início de várias sílabas ou de várias palavras em um mesmo enunciado" (DUBOIS et al., 2006, p.40). Com isso, encontramos aliteração nos versos: "A seca terrive, que tudo devora", em que temos a aliteração da oclusiva surda 't' nos vocábulos terrível e tudo. Identificamos ainda, o fenômeno da aliteração no verso "Aquele nortista, partido de pena", com as oclusivas 't' e ' $p$ ', respectivamente.

Por último, observemos as estrofes 11, 12, 13 e 14: 


\section{(Estrofe 11)}

No dia seguinte, já tudo enfadado,

E o carro embalado,

Veloz a corrê,

Meu Deus, meu Deus

Tão triste, o coitado, falando saudoso,

Um seu fio choroso

Escrama, a dizê:

Ai, ai, ai, ai

\section{(Estrofe 12)}

- De pena e saudade, papai, sei que morro!

Meu pobre cachorro,

Quem dá de comê?

Meu Deus, meu Deus

Já ôto pergunta: - Mãezinha, e meu gato?

Com fome, sem trato,

Mimi vai morrê!

Ai, ai, ai, ai

\section{(Estrofe 13)}

E a linda pequena, tremendo de medo:

- Mamãe, meus brinquedo!

Meu pé de fulô!

Meu Deus, meu Deus

Meu pé de rosêra, coitado, ele seca!

E a minha boneca

Também lá ficou.

$\mathrm{Ai}$, ai, ai, ai

\section{(Estrofe 14)}

E assim vão dexando, com choro e gemido,

Do berço querido

$O$ céu lindo e azu.

Meu Deus, meu Deus

$O$ pai, pesaroso, nos fio pensando,

$\mathrm{E} o$ carro rodando

$\mathrm{Na}$ estrada do Su.

$\mathrm{Ai}$, ai, ai, ai

Nas estrofes de 11 a 14, o que nos chama atenção é a predominância de vocábulos nos quais há o uso insistente das vogais orais posteriores, mais 
precisamente, o ' $u$ ' e 'o'. Segundo Martins (2000, p. 32, grifos nossos), "a série posterior tem a possibilidade de imitar sons profundos, cheios, graves, ruídos surdos, e sugere ideia de fechamento, redondeza, escuridão, tristeza, medo, morte". Das potencialidades expressivas atribuídas à esses sons, percebemos que as ideias de tristeza e medo são realçadas pelo uso recorrente das vogais em destaque como nos versos: "Tão triste, o coitado, falando saudosol Um se u fio choroso [...] E assim vão dexando com choro e gemido/ O pai, pesaroso, nos fio pensando".

De igual modo, as ideias de medo e morte são reforçadas por meio do aproveitamento das vogais posteriores nos seguintes versos: "De pena e de saudade, papai sei que morro!/ Meu pobre cachorro/ Quem dá de comê?", bem como em: "Já ôto pergunta: - Mãezinha, e meu gato? Com fome, sem trato/ Mimi vai morre!". A sensação ou ideia de redondeza também é reforçada pela insistência das posteriores nos versos: "E o carro rodando/ Na estrada do Su".

Importante colocar que, tanto no caso das vogais posteriores, como no das consoantes oclusivas ' $p$ ', ' $d$ ', ' $b$ ', ' $t$ ', tratadas anteriormente, estamos assumindo algum tipo de correlação entre esses sons e as ideias que são expressas pelos vocábulos nos quais aparecem. Assim, temos a chamada neutralização da arbitrariedade do signo linguístico, que se dá por meio da transferência sonora (PORZIG, 1970; MARTINS, 2000), conforme discutimos na seção 1 deste trabalho.

Frisamos, ainda, que a repetição das vogais produz também uma famosa figura do som muito aproveitada e produtiva no sistema expressivo da língua, isto é, a assonância. Em linhas gerais, o fenômeno da assonância é marcado pela "repetição vocálica em sílabas tônicas [...]; mas a mesma vogal pode aparecer não acentuada, prologando a insistência" (MARTINS, 2000, p. 38). Dentre outros, é possível, portanto, identificar ainda na estrofe 11 assonância das vogais posteriores nos seguintes versos: "No dia seguinte, já tudo enfadado, E o carro embalado/Veloz a corrê".

Ao longo desta seção, abordamos a presença de alguns recursos compreendidos, aqui, como estilísticos/expressivos na letra da canção $A$ triste partida. Evidentemente, analisamos apenas alguns dos muitos recursos que podem ser observados na letra da canção em foco, isso indica que, além dos fenômenos que discutimos, outros merecem destaque. É preciso reconhecer também que, outras leituras realizadas a partir de outras perspectivas teóricas, podem ser feitas e certamente proporcionariam uma compreensão ainda maior de algumas questões abordadas pelos compositores na letra da canção. Isso nos leva a crer, portanto, que a leitura que apresentamos, neste artigo, figura como uma das muitas possíveis para a interação entre os recursos estilísticos/expressivos de $A$ triste partida. Contudo, nos sentimos satisfeitas, por ora.

\section{CONSIDERAÇÕES FINAIS}

Discutimos, ao longo deste texto, algumas das propostas de análise dos recursos estilísticos/expressivos da linguagem proporcionadas pela Estilística do som (BALLY, 1941, 1951; GRAMMONT, 1975; GILI, 1971; MORIER, MARTINS, 2000). A partir disso, redimensionamos esses postulados para a letra da canção $A$ triste partida, cantada por Luiz Gonzaga. Nosso intuito maior foi identificar alguns dos fenômenos da linguagem estilística/expressiva presentes na letra da canção e, 
com base na interação entre eles, observar a intensificação dos sentimentos de saudade, tristeza e angústia que acometem os personagens da canção, ao precisarem deixar a terra natal por causa dos longos períodos de seca que atingiam/atingem algumas localidades da região nordeste e que eram/são agravados pelo descaço político. Além disso, buscamos observar como alguns recursos estilísticos/expressivos aparecem como uma tentativa de representar aspectos dialetais dos personagens da canção.

Dentre os fenômenos expressivos que marcam a letra de $A$ triste partida, identificamos a presença de diferentes tipos de rima, homeoteleutos, assonância, aliteração e diversas alterações fonético - fonológicas, além da constante ênfase em determinados sons. Acreditamos que os efeitos estilísticos/expressivos provocados por tais fenômenos reforçam os sentimentos de angústia, sofrimento e desespero dos personagens da canção ao se verem obrigados a deixar sua terra natal, para não morrerem de fome e de sede, tal como supomos inicialmente.

No que concerne à presença de recursos estilísticos/expressivos para tentar representar aspectos dialetais dos personagens, vimos que, de fato, ao longo da letra da canção, é possível identificar inúmeras alterações fonético-fonológicas que embora sejam apenas tentativas de representação - remetem traços da linguagem usada por camadas sociais desfavorecidas economicamente e que tendem a ser associadas à determinadas regiões do Brasil, mais especificamente, ao interior nordestino. Sobre esse último ponto, salientamos que, para nós, tais aspectos dialetais aparecem na canção com o intuito de marcar também o sentimento de identidade e pertencimento dos personagens à sua terra natal.

Ao término deste trabalho, estamos convencidas de sua significativa contribuição para as discussões em torno do fenômeno da expressividade linguística da língua portuguesa que, aliás, há tempos é devidamente explorada por poetas, escritores, músicos, bem como em vários outros tipos de discurso (CÂMARA JR., 1978; MARTINS, 2000; MONTEIRO, 2005). Acreditamos ainda nas contribuições deste estudo para as discussões sobre a inestimável riqueza da música de Luiz Gonzaga.

Naturalmente, estamos cientes também das limitações desta pesquisa para uma abordagem mais aprofundada da obra de Luiz Gonzaga, dada a evidente complexidade que a envolve. De igual modo, sinalizamos que pontos como a representação do Nordeste, do nordestino, do caráter de denúncia da exploração e descaso político que agravam o problema da seca em algumas localidades da região Nordeste brasileiro, conforme vimos ao longo da letra de $A$ triste partida, merecem ser mais bem explorados em trabalhos futuros.

\section{ABSTRACT:}

In the light of Stylistics Sound or Phonostylistics (BALLY, 1941, 1951; GRAMMONT, 1975; GILI 1971; MORIER, 1975; MARTINS, 2000), we analyzed in this work, the lyrics of the song $A$ triste partida, sung by Luiz Gonzaga - also known as the King of the Baião. Our objective is to describe and reflect on the stylistic/expressive effects of phonological-phonetic resources, such as phonemes and sound figures, present in the lyrics of the song. To do so, we closely observe the stanzas that compose the lyrics of the $A$ triste partida and describe some of the main stylistic/expressive 
features that compose. The analyzes indicate the presence of stylistic/expressive language resources such as homeoteleuto, rhymes, alliteration, assonance, phonetic-phonological alterations in some vocables, among others.

KAYWORDS: Stylistics of the sound; A triste partida; Analysis.

\section{REFERÊNCIAS}

ARAÚJO, A. A. de. A monotongação na norma culta de Fortaleza. 110f. 2007. Dissertação (Mestrado em Linguística), Universidade Federal Ceará, Fortaleza, CE, 2007.

A monotongação do ditongo [ej] no projeto Atlas Linguístico do Brasil: uma abordagem variacionista. Confluência, Rio de Janeiro, v. Único, p. 289-308, 2013. Disponível em: http://lp.bibliopolis.info/confluencia/pdf/1219.pdf. Acesso em: 09 Ago. 2017.

BAGNO, M. Nada na língua é por acaso. Por uma pedagogia da variação linguística. 6. imp. São Paulo: Parábola Editora, 2016.

Sete erros aos quatro ventos: a variação linguística no ensino de português. São Paulo: Parábola Editora, 2013.

BALLY, C. El linguaje y la vida. Trad. de Amado Alonso. Buenos Aires: Ed. Losada, 1941.

. Traté de Stystique Français. 3 ed. Paris-Genebra: Librarie KlincksieckLibrairie Geog e Cie, 1951.

CÂMARA JR. J. M. Contribuições à Estilística portuguesa. Rio de Janeiro: Ao Livro Técnico, 1978.

CRYSTAL, D.; DAVY, D. Investigation English style. Londres: Longmans, 1969.

DUBOIS, J. et. al. Dicionário de Linguística. Direção e coordenação geral da tradução Izidoro Blikstein. São Paulo: Cultrix, 2006.

FARACO, C. A. Norma culta brasileira: desatando alguns nós. São Paulo-SP, Parábola Editora, 2008.

GILI, G. S. Elementos de fonética geral. Madri: Gredos, 1971.

GRAUMMONT, M. Traté de phonétique. 4 ed. Paris: Delagrave, 1975.

INFANTE, U. Textos: leituras e escritas. vol. único. São Paulo: Editora Scipione, 2004

JAKOBSON, R. Linguística e comunicação. Tradução de Izidoro Blikstein. 4 ed. rev. São Paulo: Cultrix, 1970.

LEON, P. R. Essais de phonostylistique. Studia fonética. 4 ed. Paris: Delagrave, 1971.

LEVIN, S. Estruturas linguísticas em poesia. Tradução de José Paulo Paes. São Paulo: Cultrix/EDUSP, 1975.

MARTINS, N. S. A. Introdução à Estilística: a expressividade na língua portuguesa. 3 ed. rev. e num. São Paulo: T. A. Queiroz, 2000.

MORIER, P. Dictionnare de poétique et de retorique. 2 ed. Paris: PUF, 1975.

MONTEIRO, J. L. A Estilística. São Paulo: Vozes, 2005. 
Aplicações dos estudos estilísticos. Revista ABRAFIL, n. 8, p.84-90, 2011. Disponível em: http://www.filologia.org.br/abf/rabf/8/084.pdf. Acesso em: 29 Jan. 2017.

PEREIRA, G. A monotongação dos ditongos $<e j>$, <ow $<$ e <aj> no português falado em Tubarão (SC). estudo de casos. 134f. 2004. Dissertação (Mestrado em Ciências da Linguagem), UNISUL, Tubarão, SC, 2004. Disponível em: http://busca.unisul.br/pdf/73807 Gerusa.pdf. Acesso em: 6 de Ago. 2016.

PORZIG, W. El mundo maravilhoso del linguaje. Versão espanhola de Abelardo Moralejo. 2 ed. Madri: Gredos, 1970.

RIFFATERRE, M. Estilística Estrutural. Trad. de Anne Amichand e Álvaro Lorencini. São Paulo: Cultrix, 1973.

SAUSSURE, F. de. Curso de Linguística Geral. Organizado por Charles Bally, Albert Sechehaye com a colaboração de Albert Riedlinger. Trad. de Antônio Chelini, José Paulo Paes e Izidoro Blikstein. 34 ed. São Paulo-SP: Cultrix, [1916] 2012.

SILVA, F. de S. O processo de monotongação em João Pessoa. In HORA, D. da. Estudos Sociolinguísticos: perfil de uma comunidade. João Pessoa: CNPq/ILAPEC/VALPB, 2004, p.29- 44.

SPITZER, L. Linguística e história literária. Trad. de José Perez Riesgo. 2 ed. Madri: Gredos, 1968.

TOLEDO, E. E. A monotongação do ditongo decrescente [ej] em amostra de recontato de Porto Alegre. 109f. 2011. Dissertação (Mestrado em Linguística), PUCRS, Porto Alegre, RS, 2011. Disponível em: http://hdl.handle.net/10183/39409. Acesso em: 10 Ago. 2017.

VEADO, R. M. A. Redução de ditongo - uma variável sociolinguística. Ensaios de Linguística. Belo Horizonte (MG), ano v, n. 9, p. 209 - 229, 1983. Disponível em: http://www.periodicos.letras.ufmg.br/index.php/clt//article/view/7199. Acesso em 15 Ago. 2017. 